\title{
Os Novos Instrumentos de Planejamento do Sistema Francês de Gestão de Recursos Hídricos: II - Reflexões e Propostas para o Brasil
}

\author{
Antônio Eduardo Leão Lanna, Jaildo Santos Pereira \\ Instituto de Pesquisas Hidráulicas da Universidade Federal do Rio Grande do Sul - Caixa Postal 15029 \\ 91501-970 Porto Alegre, RS - lanna@iph.ufrgs.br, jaildo@yahoo.com \\ Gilles Hubert \\ Centre d'Enseignement et de Recherche Eau, Ville et Environnement - CEREVE - 6-8, avenue Blaise Pascal \\ Cité Descartes - Champs sur Marne - 77455 Marne La Vallée - CEDEX 2 - France - hubert@cereve.enpc.fr
}

Recebido: 10/04/01 - revisão: 19/04/02 - aceito: 17/05/02

\begin{abstract}
RESUMO
A legislação brasileira estabelece que os planos de recursos hídricos deverão ser elaborados aos níveis nacional, estadual e de bacias hidrográficas, sendo que este último pode ainda ser de rios de domínio estadual ou federal. Partindo de uma análise da legislação, o presente artigo apresenta como estes planos estão sendo elaborados nos diversos Estados, discute algumas alternativas de integração e, finalmente, baseado na recente experiência francesa de elaboração dos SDAGE e SAGE, apresentado em artigo anterior pelos mesmos autores, faz algumas recomendações para o processo de planejamento de recursos hídricos no Brasil.
\end{abstract}

Palavras-chave: instrumentos de gestão dos recursos hídricos; planejamento dos recursos hídricos; gerenciamento de recursos hídricos.

\section{INTRODUÇÃO}

A Lei 9.433/97 da Política Nacional de Recursos Hídricos dispõe que os Planos de Recursos Hídricos deverão ser elaborados por bacias, por Estados e para o país (art. $8^{\circ}$ ), sendo planos diretores que visam a fundamentação e a orientação da implementação da Política Nacional de Recursos Hídricos e o gerenciamento de recursos hídricos $\left(\right.$ art. $6^{\circ}$ ). São planos de longo prazo, com horizonte de planejamento compatível com o período de implantação de seus programas e projetos, e terão o seguinte conteúdo mínimo $\left(\operatorname{art.~} 7^{\circ}\right)$ :

1. diagnóstico da situação atual dos recursos hídricos;

2. análise de alternativas de crescimento demográfico, de evolução de atividades produtivas e de modificações dos padrões de ocupação do solo;

3. balanço entre disponibilidades e demandas futuras dos recursos hídricos, em quantidade e qualidade, com identificação de conflitos potenciais;
4. metas de racionalização de uso, aumento de quantidade e melhoria de qualidade dos recursos hídricos disponíveis;

5. medidas a serem tomadas, programas a serem desenvolvidos, e projetos a serem implantados, para o atendimento das metas previstas;

6. responsabilidades para a execução das medidas, programas e projetos;

7. cronograma de execução e programação orçamentário-financeira associados às medidas, programas e projetos;

8. prioridades para outorga de direitos de uso dos recursos hídricos;

9. diretrizes e critérios para a cobrança pelo uso dos recursos hídricos;

10. propostas para a criação de áreas sujeitas à restrição, com vistas à proteção dos recursos hídricos.

Da forma como a lei é apresentada pode-se deduzir que a situação esquematizada na Figura 1 é encontrada no processo de planejamento de recursos hídricos no país. 


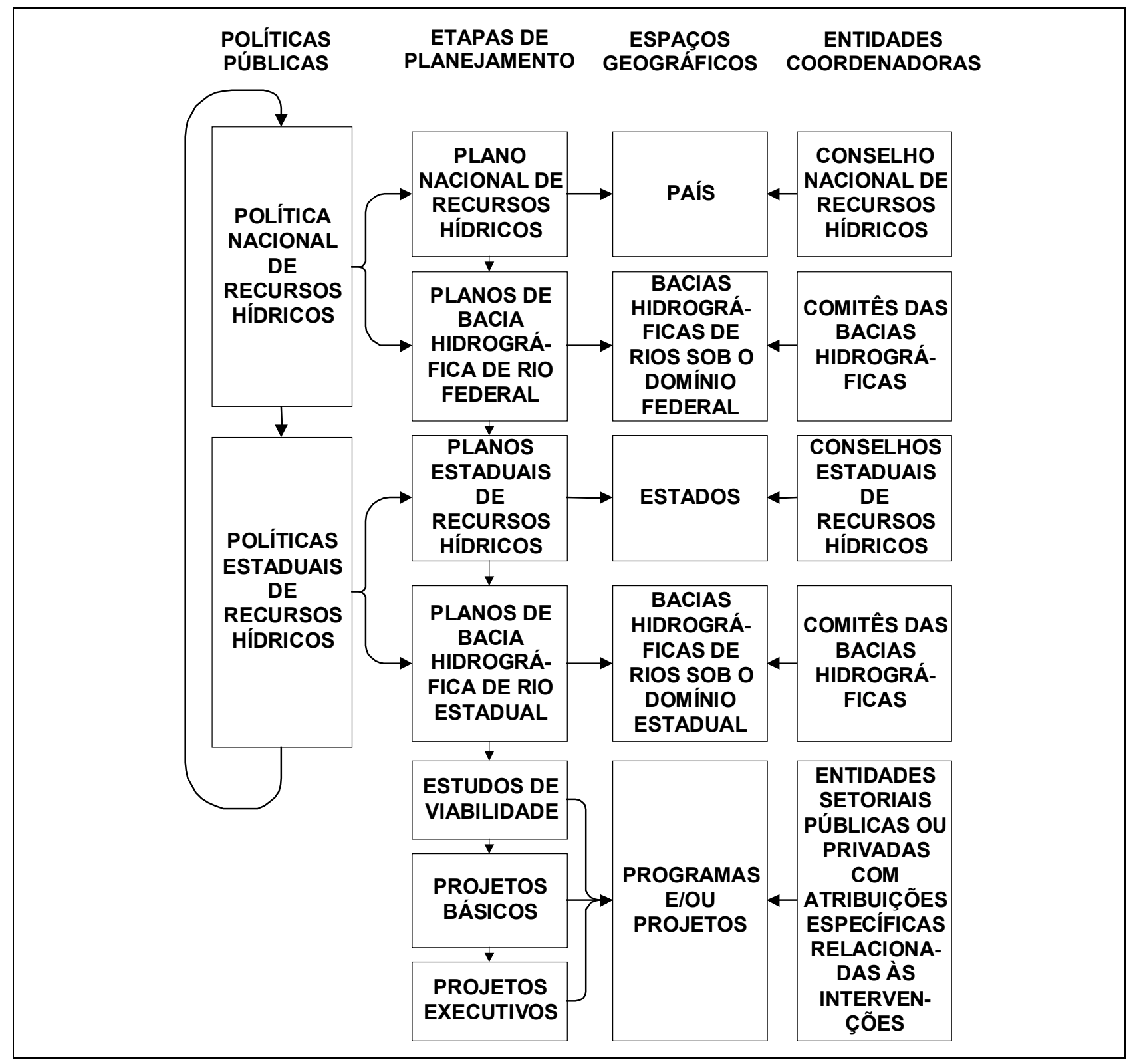

Figura 1. Políticas públicas, tipos de planos, âmbitos geográficos e entidades coordenadoras no processo de planejamento de recursos hídricos no Brasil.

As Políticas Nacional e Estaduais de Recursos Hídricos são aprovadas nas respectivas instâncias e estabelecem as grandes diretrizes de planejamento e gestão. Três tipos de planos podem ser concebidos: o Plano Nacional, os Planos Estaduais de Recursos Hídricos e Planos de Bacias Hidrográficas. Estes últimos podem inserir dois tipos de bacia: aquelas em que os cursos de água se inserem totalmente em um único Estado - Plano de Bacia Hidrográfica de Rios sob domínio Estadual - e aquelas que alguns cursos de água se inserem em mais de um Estado - Plano de Bacia Hidrográfica de Rios sob domínio Federal. As entidades coordenadoras de cada um desses planos são também apresentadas. Exemplos que ilustram a situação, seria a convivência de um Plano Nacional de Recursos Hídricos, com o Plano da Bacia Hidrográfica do rio São Francisco, com os Planos Estaduais de Recursos Hídricos dos Estados que se inserem parcialmente nesta bacia (Goiás, Distrito Federal, Minas Gerais, Bahia, Pernambuco, Alagoas e Sergipe), com os planos das bacias hidrográficas de rios sob domínio de qualquer um destes Estados, como o da bacia hidrográfica do rio das Velhas, Minas Gerais, rio Grande, Bahia, etc. 
O que deve parecer claro é que estes planos devem, por um lado, ser integrados. Por outro lado, eles devem se complementar, não cabendo que um seja mera repetição de outro. Parece igualmente lógico que os planos que são relacionados com âmbitos espaciais mais amplos (por exemplo, Nacional ou Estaduais) devem ser realizados com menor nível de detalhe que aqueles relativos a âmbitos espaciais mais restritos, como os de bacia hidrográfica. A mesma lógica estabelece que os primeiros planos, Nacional e Estaduais, tenham ênfase na coordenação das atividades, na compatibilização das demandas e na integração das estruturas de planejamento e de gestão nos âmbitos espaciais mais restritos da bacia hidrográfica. Estas questões serão analisadas e desenvolvidas a seguir.

\section{INTEGRAÇÃO DOS DIVERSOS ÂMBITOS DE PLANEJAMENTO}

Duas alternativas de integração são apresentadas: na primeira, mais imediata, a integração seria por agregação dos planos e é esquematizada na Figura 2. Cada plano seria elaborado pela instância prevista em lei: Comitê de Bacia Hidrográfica ou Órgão Gestor de Recursos Hídricos, sob a orientação do respectivo Conselho de Recursos Hídricos. O Plano Estadual de Recursos Hídricos seria obtido pela agregação dos Planos de Bacia Hidrográfica dos rios sob domínio estadual; os Planos de Bacia Hidrográfica de rios sob domínio federal agregariam os Planos dos Estados que compartilham a bacia, naquilo que disponham sobre ela; finalmente, o Plano Nacional de Recursos Hídricos seria uma agregação de todos os planos anteriores.

Esta concepção apresenta duas falhas. Primeiro, ela pressupõe que a agregação seja possível, ou seja, que não existam conflitos entre as demandas e interesses de uma bacia em relação às outras, ou em relação as políticas setoriais que sejam coordenadas no âmbito nacional, como a de energia elétrica. Segundo, este processo de agregação poderia resultar em planos repetitivos e cada vez maiores no conteúdo e na abrangência espacial.

A pressuposição de que não existam conflitos de interesse é obviamente errônea. O processo de planejamento de recursos hídricos é necessário exatamente devido a esta possibilidade. Os planos de maior abrangência deveriam compatibilizar os interesses dos âmbitos mais restritos, expressos nos seus planos específicos. Isto, porém, resultaria em um processo de planejamento ineficiente, pois as demandas realizadas, por exemplo, no âmbito de uma bacia de rio sob o domínio estadual, poderiam não ser acatadas no plano estadual ou poderiam estabelecer conflitos com as demandas de uma bacia de rio sob o domínio federal que a contém. Diante disto, o processo de planejamento, no que se refere à demanda não atendida estaria prejudicado ou não resultaria na necessária harmonia entre os diversos âmbitos de interesse.

Diante disto, propõe-se a opção de integração apresentada na Figura 3. Nesta situação as demandas dos âmbitos mais restritos são consideradas no preparo dos planos nos âmbitos mais amplos, pois os órgãos com atribuições de preparar os planos destes âmbitos mais restritos apresentariam previamente ao preparo dos planos dos âmbitos mais abrangentes suas sugestões e/ou reivindicações com relação ao que nestes planos possa afetá-los. Estes planos de âmbitos mais abrangentes, ao contrário de entrar em detalhes, buscam compatibilizar:

- as demandas dos âmbitos mais restritos entre si;

- as demandas sobre os recursos hídricos com as demandas sobre os demais recursos ambientais, provenientes dos vários setores ou de interesses relacionados à proteção ambiental, em termos gerais, geralmente através de diretrizes globais para usos dos instrumentos de gestão ou para qualquer tipo de intervenção nas águas.

Isto estabelece um processo de planejamento novamente na forma de um carrossel no qual as demandas dos âmbitos mais restritos são processadas nos âmbitos mais amplos, gerando orientações, na forma de diretrizes de planejamento, que deverão ser acatadas. Um exemplo deve esclarecer melhor esta dinâmica. Seja a bacia do rio São Francisco, compartilhada por vários Estados brasileiros e com importantes aproveitamentos hidroelétricos. Comitês de bacias de rios afluentes do São Francisco, alguns sob o domínio estadual, acham-se em implantação em alguns Estados, como em Minas Gerais. Estes comitês, representando os interesses locais, canalizarão suas demandas tanto ao Órgão Gestor e ao Conselho Estadual de Recursos Hídricos respectivo, quanto ao Comitê da Bacia do São Francisco. Estas demandas serão negociadas e compatibilizadas com os interesses mais gerais do Estado, e com os interesses de toda a bacia do rio São Francisco. Note-se que esta última compatibili 


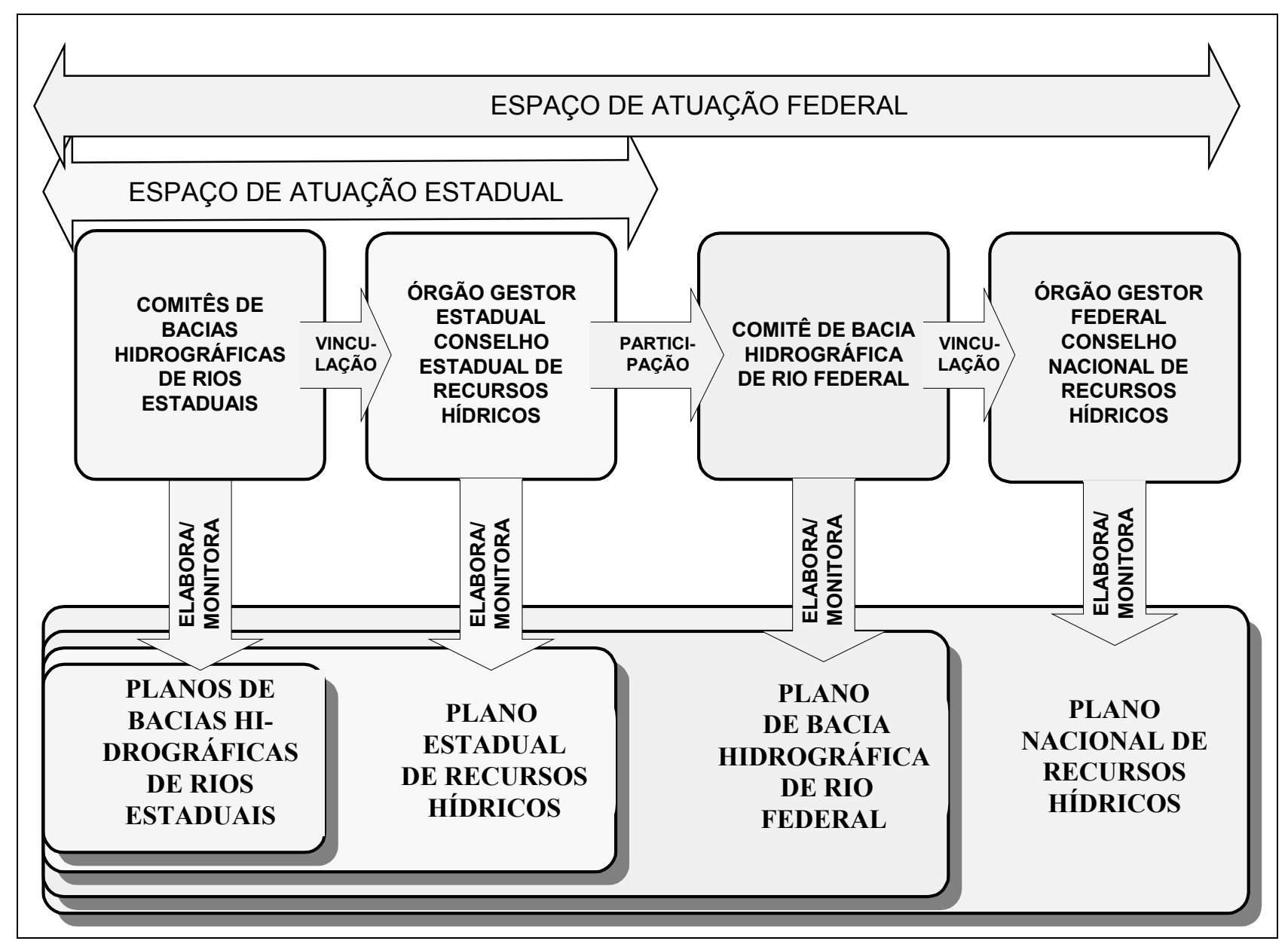

Figura 2. Integração dos âmbitos de planejamento por agregação.

zação não interfere demasiadamente nas atribuições que o Estado tem na destinação das águas sob o seu domínio - afinal, o Comitê da Bacia do São Francisco será composto por representantes dos usuários de água de todos os Estados, das entidades públicas que atuam na bacia, inclusive as estaduais, e por representantes de organizações da sociedade civil, que atuam em toda a bacia. Logo, os interesses específicos de uma sub-bacia estarão representados de diversas maneiras. Por sua vez, o Comitê da Bacia do São Francisco estabelecerá demandas a serem consideradas pelo Órgão Gestor de Recursos Hídricos Federal e o Conselho Nacional de Recursos Hídricos.

As questões de interesse local, cujas conseqüências não ultrapassam os limites de uma subbacia, poderão ser resolvidas nos respectivos comitês - estas deverão ser a maioria. Apenas aquelas cujos impactos extrapolem a sub-bacia necessitam ir mais além: ao Estado, ao Comitê da Bacia do São Francisco e, em último caso, ao âmbito federal.
Por exemplo, quando houver conflitos relacionados à qualidade de água usada para abastecimento de cidades à jusante de lançamentos de efluentes, suas negociações poderão ser restritas ao Comitê de Bacia que as contenha, ou ao Estado onde ocorre este problema. Quando houver disputa entre o uso de água para a irrigação e para a geração de energia, o âmbito correto é o Comitê da Bacia do São Francisco, preliminarmente, onde ambos os tipos de usuário estarão presentes. No caso de impasse, caberia à solução ao âmbito federal. No caso de transposição das águas do São Francisco para Estados fora da bacia, o âmbito decisório é necessariamente o federal, por extrapolar ao âmbito da bacia.

Os planos de âmbito mais geral deverão entrar em maiores detalhes apenas nas questões que são de sua alçada. Sempre que as questões puderem ser tratadas em âmbitos mais restritos, isto deverá ser feito. Esta proposta incorpora alguns princípios à atividade de planejamento que merecem ser identificados: 


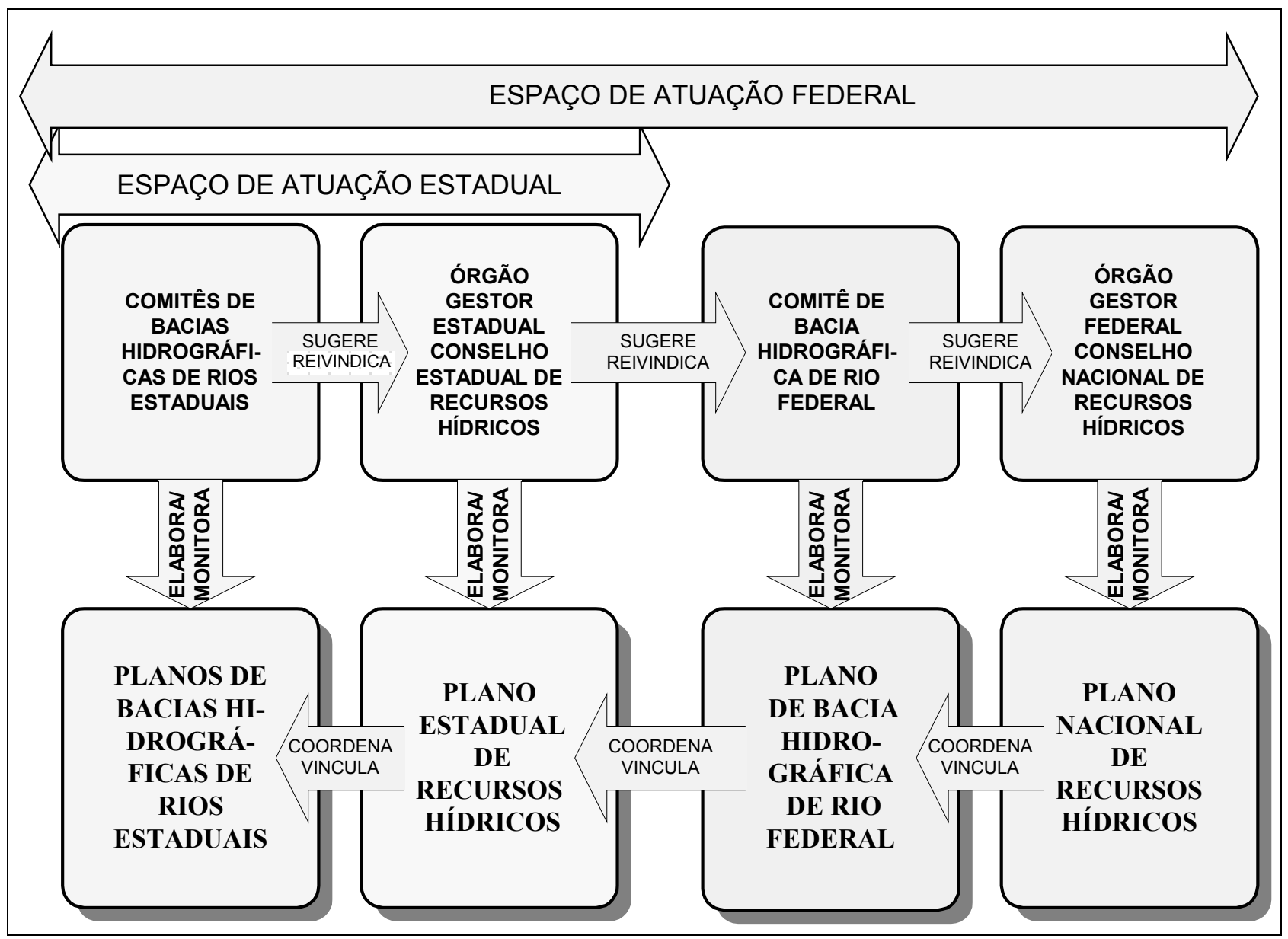

Figura 3. Integração dos âmbitos de planejamento por coordenação.

1. princípio da descentralização: por este princípio, o planejamento é descentralizado nas menores unidades possíveis, os Comitês de Bacias Hidrográficas de afluentes de rios maiores;

2. princípio da participação: este processo de planejamento induz a participação, que é mais facilitada em unidade menores de planejamento, mais próximas aos interesses dos participantes;

3. princípio do equilíbrio entre âmbito geográfico e detalhamento: por este princípio, evita-se planos demasiadamente detalhados em bacias ou unidades de grande extensão, o que poderia tornar o plano demasiadamente inflexível: para se mudar algum detalhe haveria necessidade de ser refeito todo o processo;

4. princípio de localidade: por este princípio, as questões que podem ser tratadas em âmbitos mais restritos não deverão ser levadas ao âmbitos mais amplos;
5. princípio da subsidiaridade: por este princípio, embora o processo de planejamento seja gradual e descentralizado, existe o compromisso de atender disposições e diretrizes que sejam negociadas em âmbitos mais amplos.

Este tipo de integração, na área de atuação estadual, é previsto na Lei 10.350 de 30/12/1994 da Política Estadual de Recursos Hídricos do Rio Grande do Sul. O Plano Estadual de Recursos Hídricos deverá ser elaborado com base nas propostas encaminhadas pelos Comitês de Bacia, levando também em conta propostas apresentadas individual ou coletivamente por usuários de água, planos regionais e setoriais de desenvolvimento, tratados internacionais, estudos, pesquisas e outros documentos públicos que possam contribuir para a compatibilização e a consolidação das propostas dos Comitês (art. 24). Os Planos de Bacia Hidrográfica terão por finalidade operacionalizar no âmbito de cada bacia hidrográfica as disposições do Plano Estadual de Recursos Hídricos (art. 26). 
O esquema apresentado na Figura 3 poderá ser alterado para refletir as características de algumas unidades da federação. Em certos Estados, especialmente aqueles com área territorial de pequenas dimensões, poderá ser interessante realizar o Plano Estadual de Recursos Hídricos embutindo os planos das bacias hidrográficas de rios sob o seu domínio, conforme ilustra a Figura 4. O Estado promove, através dos Comitês, o preparo simultâneo e compatibilizado dos Planos de Bacia de rios sob seu domínio gerando de forma automática o Plano Estadual.

Em Estados que os rios sob domínio federal são de pequena importância o Plano de Bacia de Rio Federal não seria necessário e o Plano Estadual estaria vinculado unicamente ao Plano Nacional, reduzindo as instâncias de planejamento.

A alternativa de integração dos âmbitos de planejamento por coordenação também apresenta algumas dificuldades, entre elas:

- o processo de planejamento em carrossel pode demandar bem mais tempo, por conseqüência das idas e vindas entre as diversas instâncias;

- diferentes estágios de desenvolvimento - a implantação dos Sistemas Estaduais de Recursos Hídricos ocorre de forma bastante diferenciada nas Unidades da Federação e isso poderá dificultar o desenvolvimento do planejamento. A realização de um plano de uma bacia como a do rio São Francisco, compartilhada por sete Estados, pode ser dificultada ou mesmo comprometida pela ausência ou morosidade de um dos Estados.

Para ilustrar um pouco mais a questão dos diferentes estágios de desenvolvimento das políticas de gestão de águas no Brasil, as leis que instituíram os sistemas estaduais de recursos hídricos em São Paulo e no Espírito Santo foram aprovadas, respectivamente, em 1991 e em 1998. Entre estas está a Lei 9433, que instituiu o Sistema Nacional de Recursos Hídricos, aprovada em janeiro de 1997.

\section{A SITUAÇÃO ATUAL DOS PLANOS DE RECURSOS HÍDRICOS NO BRASIL}

Enquanto a legislação não é devidamente regulamentada, ou as práticas operacionais não forem devidamente consolidadas, o que tem ocorrido é que os Estados têm tomado iniciativas de elaboração de Planos Estaduais e de Bacias Hidrográficas, sem uma concatenação uniforme. Alguns Estados, como a Bahia, têm entendido que o Plano Estadual deve ser realizado posteriormente e tendo por referência as propostas dos Planos de Bacia Hidrográfica. Outros, como o Rio Grande do Sul, entendem que o Plano Estadual deve anteceder e orientar/vincular a realização dos Planos de Bacia Hidrográfica.

Ao tomar iniciativas de elaborar seus Planos Estaduais de Recursos Hídricos, muitos Estados têm elaborado planos de bacias de rios de domínio estadual que são afluentes de rios de domínio federal. Obviamente, será necessário realizar a compatibilização entre os planos dessas bacias e os planos mais gerais da bacia hidrográfica em sua totalidade.

De forma geral, essa compatibilização será relativamente simples quando se tratar de bacias hidrográficas de menor extensão ou de situação pouco complexa. Entretanto, deverão ocorrer grandes dificuldades em bacias como a do rio São Francisco, por envolver interesses de múltiplos Estados.

Para ilustrar o grau de dificuldades nesta etapa de compatibilização vide o caso da Bahia, que já elaborou a primeira versão dos planos de bacias dos rios de seu domínio, dentre eles vários que são importantes afluentes do rio São Francisco e, com base nestes, elabora seu plano estadual de recursos hídricos. Como ficarão esses planos com a perspectiva de reversão das águas do rio São Francisco? Outro caso que merece atenção especial é o da bacia do rio Paraíba do Sul, pelas complexidades política e institucional que envolve.

A Tabela 1 resume as principais características dos planos estaduais de recursos hídricos de alguns Estados e apresenta o atual estágio de desenvolvimento dos Planos de Recursos Hídricos em geral.

Além das dificuldades metodológicas, conceituais e legais já comentadas, Barth (2000) destaca algumas condições sob as quais estes planos são desenvolvidos que dificultam ou comprometem a qualidade do produto final:

- contratação de empresas privadas de consultoria especializada, com base em licitações públicas, em que o preço oferecido é, muitas vezes, determinante para a escolha da empresa vencedora;

- dificuldade dos organismos públicos contratantes para definição dos Termos de Re- 


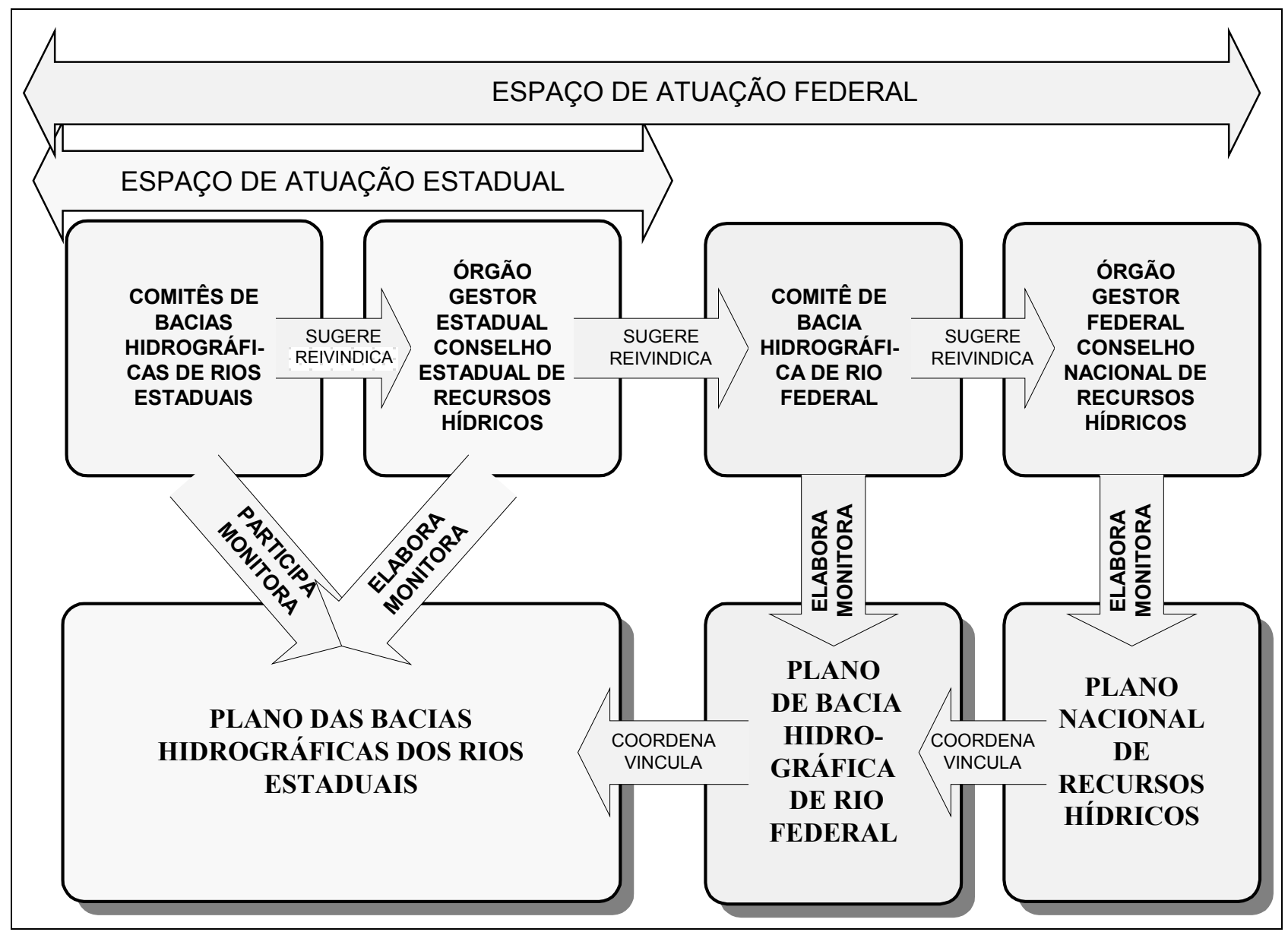

Figura 4. Adaptação a Estados que façam de seu Plano Estadual um documento mais restrito.

ferência dos trabalhos a serem realizados e, subseqüentemente, para acompanhamento e fiscalização dos trabalhos em razão de não contar com equipes técnicas multidisciplinares, indispensáveis para o campo dos recursos hídricos;

- impossibilidade das empresas contratadas em realizar os trabalhos com a qualidade desejável, em razão dos preços deprimidos ou pelas restrições orçamentárias que limitam, por exemplo, o levantamento de dados básicos e a utilização de tecnologias recentes e inovadoras;

- a dificuldade das empresas de consultoria de incorporar, ao longo do processo de planejamento, as decisões de ordem política e institucional, de forma a permitir que o plano a ser proposto seja aceito e adotado por todos os órgãos e entidades intervenientes.

Freqüentemente, em decorrência desses fatores, os planos de recursos hídricos são apenas extensos diagnósticos, com muitos volumes, mais ou menos aprofundados, conforme a disponibilidade de dados, de profissionais experientes, tanto na execução como no acompanhamento dos trabalhos e as suas conclusões e recomendações acabam por ser aceitas ou não, na dependência exclusiva de fatores favoráveis, de ordem política ou institucional, bastante incertos.

Além disso, não existe nenhuma garantia de que os outros setores, diferentes do domínio da água (agricultura, mineração, por exemplo) vão acatar as recomendações contidas nos planos de recursos hídricos.

\section{AS LIÇÕES EXTRAÍDAS DO PROCESSO DE PLANEJAMENTO FRANCÊS}

O modelo francês, implantado a partir de 1964, serviu de inspiração para todo o arcabouço legal e institucional do sistemas brasileiro de gestão de águas. Muitas das questões que atualmente des- 
Tabela 1. Características do Plano Nacional de Recursos Hídricos - PNRH, de alguns Planos Estaduais de Recursos Hídricos PERH e estágio atual do desenvolvimento dos Planos de Recursos Hídricos em geral.

Características do PNRH

Plano Nacional de Recursos Hídricos

Planos diretores que visam fundamentar e orientar a implementação da Política Nacional de Recursos Hídricos e o gerenciamento dos recursos hídricos. De longo prazo, com horizonte de planejamento compatível com o período de implantação de seus programas e projetos.

\section{Características do PERH}

São Paulo

O Plano Estadual de Recursos Hídricos - PERH será elaborado com base nos planos de suas bacias hidrográficas, nas normas relativas à proteção do meio ambiente, nas diretrizes do planejamento e gerenciamento ambientais; terá atualizaçôes periódicas e será aprovado por lei, cujo projeto será encaminhado à Assembleia Legislativa até o final do primeiro ano de mandato do Governador do Estado, com prazo de vigência de quatro anos. As diretrizes e necessidades financelras para elaboração e implantação do PERH deverão constar das leis sobre o plano plurianual, diretrizes orçamentárias e orçamento anual do Estado.

O Plano Estadual de Recursos Hídricos - PERH será elaborado, quadrienalmente, com base nos planos de suas bacias hidrográficas e em consonância
com o Plano Mineiro de desenvolvimento integrado e o Plano Plurianual de Ação Governamental. O anteprojeto de lei do PERH será aprovado pelo Conselho Estadual de Recursos Hídricos e encaminhado, na forma de projeConselho Estadual de Recursos Hidricos e encaminhado, na forma de projeto de lei, à Assembleia Legislativa pelo Governador do Estado, até o final do primeiro ano de mandato. As diretizes e a pro Estadul de Recos financeiros para a elaboraçáo e a inplantaçăo do Plano Estadul de Recursos Hidricos deverão constar nas leis relativas ao plano plurianual, nas diretrizes orçamentárias e ao orçamento anual do Estado.

O Plano Estadual de Recursos Hídricos - PERH será elaborado em consonância com os princípios e as diretrizes da Política Estadual de Recursos nância com os princípios e as diretrizes da Pollica Estadual de Recursos Hidricos e com base nos planos de suas bacias hidrograficas, observadas as normas relativas a proteção do meio ambiente, às diretrizes do Plano Plurianual do Estado e demais normas desta Lei. A constituição estadual (Art. 199) obriga o Estado a instituir por lei, e manter atualizado o PERH, congregando os organismos escos defing dos recursos hídricos e o rateio dos custos das respectivas obras.
Situação dos Planos de Bacia Hidrográfica

Situação atual do PNRH

de Rio Federal

Diversos planos foram contratados, especialmente em bacias afluentes do rio São Francisco, que são de domínio estadual. O Plano da Bacia do Rio São Francisco, propriamente dito, não foi ainda elaborado, apesar de diversas intenções nesse sentido.

\section{Planos de Bacias Hidrográficas}

Elaborado para as bacias críticas - Alto Tietê, Piracicaba e Baixada Santista, por

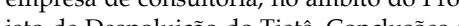
jeto de Despoluiçáo do Tiete. Conclusoses recomendaçōes não foram consensuais em razão dos conflitos institucionais e políticos a respeito do reservatório Billings. Programas de Investimento formulado para as bacias dos rios Piracicaba, Capivari, Jundiaí e Paraiba do Sul, no âmbito do Programa de Qualidade da Águas PQA/SEPURB/MPO/BIRD. Comitês de Bacias elaboraram Relatórios de Situação e apresentaram propostas para o Programa de Investimentos do Plano Estadual.

Planos de bacias hidrográficas em elaboração, inclusive em bacias de rios de domínio federal. Na bacia do rio São Francisco plano somente refere-se ao território miGro. No caso do Jequitinhonha e Verde Grande está incluido o territónio baiano, havendo entendimentos com a SRH/BA. Cogita-se ainda un Plan a de GerenciaComitês de Ba-

Planos de bacias contratados com empresas de consultoria, licitações baseadas em menor preço. ç̃o no conté́do dos planos há deficienci por falta de dados de boa qualidade epelas restricões planos incluíram cadastro de usuários.
Um Plano Nacional de Recursos Hídricos, elaborado pela Secretaria de Recursos Hídricos do Ministério do Meio Ambiente, apresentou um diagnóstico dos problemas de recursos hídricos das oito grandes bacias brasileiras, sem ter sido até o momento devidamente divulgado e discutido pelos atores. Caberia a um plano nesse âmbito, pelo menos, estabelecer diretrizes para a integração do processo de planejamento nas bacias de rios sob o domínio da União.

Situação atual do PERH

Primeiro Plano, 1991 - documento abrangente, com visão estratégica e elementos institucionais; aprovado por decreto, execução direta, por entidades pú-

Segundo Plano - aprovado por lei, contendo diretrizes gerais e programas estaduais.

Terceiro plano - o projeto de lei, contendo diretrize e programas estaduais, discriminados por bacias, aprovados pelos respectivos Comitês foi encaminhado à Assembléia Legislativa mas não tramito adequadamente e não foi aprovado.

Quarto Plano - em elaboração, contempla três partes: Projeto de Lei; Álbum sobre a Situação dos Recursos Hídricos do Estado; Programa de Investimentos para o período 2000/2003.

Plano deverá ser elaborado com base nos planos de bacias. Acha-se em andamento preparo de licitação para contratação desse plano.

Feita licitação para contratação de empresa privada de consultoria, no âmbito do Projeto de Gerenciamento de Recursos Hídricos, com financiamento do Banco Mundial.

Dificuldades metodológicas em razão da necessidade de revisão ou atualização dos planos de bacias. 
Tabela 1. Continuação.

Características do PERH

Sergipe

O Plano Estadual de Recursos Hídricos - PERH será elaboradocom base nos planos de suas bacias hidrográficas, nas normas relativas à proteção do meio ambiente, nas diretrizes do planejamento e gerenciamento ambientais. O Plano Estadual de Recursos Hídricos será aprovado por le cujo projeto será encaminhado à Assembléia Legislativa até o final do primeiro ano do mandato do Governador do Estado, com prazo de vigência de quatro anos. As diretrizes e necessidades financeiras para elaboração e implantação do Plano Estadual de Recursos Hídricos deverão constar das leis sobre o plano plurianual, diretrizes orçamentárias e orçamento anual do Estado.

Pernambuco

O Plano Estadual de Recursos Hídricos - PERH será elaborado com base nos planos de suas bacias hidrográficas, será aprovado por lei, cujo projeto nos plan be surs ba cin hidrograficas, sera ar primeiro ano de mandato do Governador do Estado, com prazo de vigência de quatro anos. As diretrizes e necessidades financeiras para elaboração e implantação do PERH deverão constar das leis sobre o plano plurianual, diretrizes orçamentárias e orçamento anual do Estado.

Paraíba

O Plano Estadual de Recursos Hídricos será instituído por Lei, obedecidos os princípios e diretrizes da Política Estadual de Recursos Hídricos e terá como base os Planos das Bacias Hidrográficas. O projeto de Lei do PERH deverá ser encaminhado pelo Governador do Estado à Assembléia Legislativa, no máximo até o final do primeiro ano do seu mandato, com prazo de vigência igual a duração do referido mandato, fixado pela Constituição Federa

Rio Grande do Norte O Plano Estadual de Recursos Hídricos será elaborado em consonância com os princípios diretrizes da Política Estadual de Recursos Hídricos. O PERH será aprovado por Lei, e será revisto e atualizado a cada quatro anos e será inserido no Plano Plurianual de Desenvolvimento do Estado, de forma a assegurar a integração setorial em seus aspectos sociais, econômicos e ambientais.

Ceará

Plano Estadual de Recursos Hídricos - PERH será aprovado por lei, cujo projeto deverá ser encaminhado à Assembléia Legislativa até o final do primeiro ano do mandato do governador, devendo o mesmo ser revisto, atualizado e consolidado com uma periodicidade mínima de quatro anos. O Estado deve manter atualizado o PERH e assegurar recursos financeiros e mecanismos institucionais para garantir: a utilização racional das águas; o aproveitamento múltiplo dos recursos hízação racional das a o rateio de custos; o proteção das águas contra ações que possam comprometer o seu uso atual e futuro; a defesa contra eventos críticos o funcionamento do sistema de previsão de secas e monitoramento
climático.
Planos de Bacias Hidrográficas

Situação atual do PERH

Serão possivelmente incluídos no Plan Estadual de Recursos Hídricos, devido ao pequeno tamanho do Estado.

\section{Estudo de Desenvolvimento dos Recursos Hí-} dricos do Estado de Sergipe apresentado em Março de 2000. Há intenção do Estado desenvolver seu Plano Estadual de Recursos Hídricos com base em pequenos acréscimos a esse estudo.

Planos de Bacias com suporte do sisteormações e contemplados n elaboração do plano estadual.

Elaborados planos das principais bacia do Estado, como diferentes enfoques.

Tendo em vista a pequena extensão Tendo extensão do Plicações

do Plano Estadual, considera-se que
Planos de Bacias estão nele contidos.

Realizados recentemente por empresa privadas de consultoria - bacias dos rios Jaguaribe e da Região Metropolitana de Fortaleza, segundo uma nova concepção de planos de gerenciamento.
Sem informações.

Plano elaborado e disponível em versão eletrônica.

Elaborado em 1992 por consórcio de empresas de consultoria. Gerou documento técnico abo dando aspectos institucionais e de engenharia.

Fonte: adaptado de Barth (2000). 
pertam grande interesse no Brasil, especialmente no que se refere aos planos de recursos hídricos, também na França, durante muito tempo motivaram intensos debates. Basta lembrar que, apesar do sistema francês já estar em funcionamento há mais de 30 anos, os aspectos de planejamento eram até bem pouco tempo considerados embrionários, resumindo-se a cartas departamentais de objetivos de qualidade, planos diretores de águas, planos de vocação piscícola, etc. Todos estes documentos, além de serem instituídos por portarias ministeriais (em alguns casos interministeriais), não tinham valor jurídico necessário para assegurar sua obediência e seu perímetro de aplicação correspondia aos limites do território e não da bacia hidrográfica.

Em 1990 na França, o Ministério do Ambiente organizou um grande debate visando realizar um balanço sobre as ações desenvolvidas depois de 1964 e discutir soluções para melhorar a gestão de águas naquele país. Este debate vai delinear as orientações da nova lei da água, aprovada em 3 de janeiro de 1992, 28 anos após a lei original.

Esta última tem como postulado básico o reconhecimento da água como patrimônio comum da nação. Ela confere à preservação e à recuperação dos meios aquáticos um caráter de interesse geral. Evidencia o princípio da gestão equilibrada dos recursos hídricos, assegurando simultaneamente uma proteção dos ecossistemas e o atendimento aos usuários. Apesar de não causar grandes modificações nas leis existentes, ela ofereceu aos atores que intervêm no processo de gestão das águas novos instrumentos, especialmente em matéria de planejamento: os SDAGE's (Schéma Directeur d'Aménagement et de Gestion des Eaux) e os $S A G E^{\prime}$ s (Schéma d'Aménagement et de Gestion des Eaux).

Os SDAGE's estabelecem para cada uma das seis grandes bacias hidrográficas francesas as orientações fundamentais para uma gestão equilibrada dos recursos hídricos. Eles têm um caráter obrigatório e a legislação previu um prazo de cinco anos, a partir da publicação da lei, para sua elaboração.

Os SAGE's estabelecem ao nível de subbacias, correspondentes a cada uma das unidades hidrográficas ou de sistemas de aqüíferos, os objetivos de uso, desenvolvimento e proteção dos recursos hídricos e dos meios aquáticos. Eles são facultativos e a lei não fixou nenhum prazo para sua elaboração.

A primeira versão dos SDAGE's foi elaborada entre 1992 e 1997 e estão em vigor juntamente com o $7^{\circ}$ Programa das Agências de Água. Maiores informações podem ser obtidas em Hubert, Pereira e Lanna (2002). A seguir será comentado alguns aspectos dos SDAGE's e dos SAGE's que podem contribuir para o desenvolvimento do planejamento dos recursos hídricos no Brasil.

\section{Os métodos de elaboração}

Embora as atividades de planejamento sejam basicamente técnicas, as decisões de escolhas das alternativas são necessariamente políticas e por esta razão é preciso considerar que as agendas políticas são determinantes no processo de decisão.

Uma dificuldade observada no processo de elaboração dos planos de recursos hídricos brasileiros é que os demais atores intervenientes no processo de gestão de águas, terminam por ter uma participação bem modesta. Essa participação se resume ao fornecimento de informações julgadas necessárias ou expressamente solicitadas pelo organismo responsável pela elaboração do plano.

No caso francês, ao considerar o SDAGE como um contrato de desenvolvimento no domínio das águas, acordado entre os diversos atores, e ao confiar ao Comitê de bacia sua elaboração atribuiuse um peso maior às escolhas políticas. Com isso criou-se condições para maior participação dos atores envolvidos com a gestão de águas, proporcionando ainda durante a elaboração do documento a realização de negociações em torno das diversas demandas, o que confere uma maior legitimidade ao processo.

\section{O conteúdo dos documentos}

Como a lei prevê a elaboração de planos de recursos hídricos para os níveis Nacional, Estaduais e de Bacia Hidrográfica, qual deve ser o conteúdo de cada um desses planos é uma questão recorrente.

A lei nacional não faz distinção de conteúdo dos Planos Nacional, Estadual e de Bacia Hidrográfica. Apesar de que algumas leis estaduais fazem distinção entre os Planos Estaduais e dos Planos de Bacias, não só em termos de conteúdo mas também em termos institucionais e legais, a questão de qual deve ser o conteúdo de cada plano permanece, suscitando ainda muita dúvida.

No caso francês, além de apresentar uma extensão territorial relativamente modesta e tratarse de um país central, existem apenas dois diferentes domínios para a água, sendo que apenas um deles é considerado para efeito de planejamento. 
Por conseqüência a lei de águas de 1992, que criou os SDAGE's e SAGE's, definiu também o conteúdo destes documentos, reservando para o primeiro a definição das grandes diretrizes de planejamento e gestão. Os SAGE's estabelecem para o nível local os objetivos de uso, desenvolvimento e proteção dos recursos hídricos e dos meios aquáticos.

\section{Formas de apresentação}

Uma etapa muitas vezes negligenciada neste tipo de estudo é a forma de apresentação dos resultados finais. Considerando o planejamento dos recursos hídricos como uma atividade dinâmica e complexa, que requer a participação de todos os atores nos diversos estágios do processo (etapa de elaboração, etapa de implementação, etc.), é imprescindível que os resultados finais sejam do conhecimento de todos.

No caso francês, a divulgação da versão final dos SDAGE's ficou a cargo das Agências de bacias. As Agências de bacia do Rhin-Meuse e do Adour-Garonne elaboraram uma versão síntese de seus SDAGE's, em um único volume, com uma linguagem de fácil compreensão, destinado ao grande público.

Ao informar o público os resultados do SDAGE, o processo de gestão pode está ganhando um importante aliado para assegurar que as determinações contidas neste documento serão respeitadas.

\section{Implementação e continuidade}

No caso Francês, a própria legislação que criou os SDAGE's e os SAGE's atribuiu também ao comitê de bacia a tarefa de assegurar a implementação e continuidade desses instrumentos. Trata-se de cuidar:

- da compatibilidade dos grandes projetos de gestão de águas realizados na bacia em relação aos objetivos dos SDAGE's;

- da integração das orientações do SDAGE nos projetos de SAGE;

- da aplicação das decisões do SDAGE e da avaliação de seus efeitos sobre o ambiente.

A manutenção da mobilização dos atores do projeto na etapa de implementação é algo bastante desejado e a legislação ao atribuir ao comitê de bacia a responsabilidade por esta etapa fez mais uma tentativa nesta direção.

\section{CONCLUSÃO}

A gestão dos recursos hídricos no Brasil ganhou um grande impulso com a aprovação da Lei Federal 9433/97 que institui a Política Nacional de Recursos Hídricos e cria o Sistema Nacional de Gerenciamento de Recursos Hídricos. Respondendo a este esforço, até o momento 22 Estados brasileiros e o Distrito Federal já aprovaram suas respectivas leis que instituem os Sistemas Estaduais de Recursos Hídricos.

Entretanto, a aprovação dessas legislações não ocorreu no mesmo momento, evidenciando os diferentes estágios de desenvolvimento da política hídrica nos Estados. Para ilustrar esta situação, o Estado de São Paulo aprovou sua lei em 1991, Tocantins em 2002 e ainda existem outros Estados que ainda não aprovaram suas leis.

Enquanto a legislação não é devidamente regulamentada e as práticas operacionais não estão devidamente consolidadas, o que tem ocorrido é que os Estados têm tomado iniciativas de elaboração de Planos Estaduais e de Bacias Hidrográficas. Observa-se que o processo de integração destes planos está mais próximo do esquema por agregação (primeira alternativa apresentada). Ou seja, àquele que supõe ser possível a obtenção dos planos de maior abrangência pela agregação dos planos dos âmbitos mais restritos.

O planejamento dos recursos hídricos é uma tarefa extremamente complexa e requer a participação de todos os atores nas diversas etapas do processo. Além disso, não é possível indicar uma única solução. Na verdade o que existe é um conjunto de soluções. O mais importante é que os métodos adotados sejam suficientemente flexíveis e que permitam incorporar uma permanente atualização e complementação. Ou seja, a tarefa de planejar deve ser evolutiva.

A análise do caso francês permite identificar uma evolução na forma de planejar os recursos hídricos. Naquele caso, o planejamento inicialmente resumia-se a cartas departamentais de objetivo de qualidade, plano diretores de águas, planos de vocação piscícola, etc., e evoluiu para os atuais SDAGE's e SAGE's, com ganhos significativos para o processo de planejamento. Para atingir o atual estágio foram necessários quase 30 anos e, apesar dos especialistas considerarem a criação destes novos instrumentos 
um grande avanço, ainda existem pendências, especialmente em relação ao desenvolvimento dos SAGE's, que fazem com que o processo de planejamento continue precisando evoluir.

No caso brasileiro, além das dificuldades inerentes ao processo de planejamento, são dificuldades adicionais a falta de regulamentação das leis, a pouca experiência com o desenvolvimento deste instrumento e o fato de elaborar seus planos ao mesmo tempo em que o sistema de gestão de recursos hídricos está sendo implementado.

Entretanto, como o planejamento é uma atividade dinâmica, mesmo considerando as deficiências e/ou problemas enfrentados pelas experiências em curso, ela é extremamente importante pois poderá sofrer ajustes ao longo do tempo, à medida que o sistema for sendo implantado e que a experiência for sendo adquirida ou consolidada.

Finalmente, é urgente e indispensável que o aproveitamento e utilização dos recursos hídricos seja feito de forma mais eficiente e eficaz. Para isso, as atividades de planejamento são fundamentais e a elaboração dos atuais planos, desde que sejam atualizados e tenham continuidade, poderá ser um grande passo em direção à gestão global dos recursos hídricos.

\section{AGRADECIMENTOS}

$\mathrm{O}$ primeiro autor é pesquisador do $\mathrm{CNPq}$. O segundo autor desenvolveu uma parte de seu trabalho de tese no CEREVE/ENPC - França, durante o ano 2000, com o suporte da CAPES.

\section{REFERÊNCIAS}

BARTH, F. (2000). Planos de recursos hídricos. www. onelist.com/abrh-gestão.

HUBERT, G.; PEREIRA, J. S. e LANNA, A. E. (2002). Os novos instrumentos de planejamento do sistema francês de recursos hídricos: I - apresentação e análise. ABRH - RBRH (nesta edição).

\section{The New Planning Instruments of the French Water Resources Management System: II - Reflections and Proposals for Brazil}

\begin{abstract}
Brazilian Law establishes that the water resources plans should be made for national, state and river basin levels. The latter may also refer to rivers in the state or federal domain. This paper analyzes how these plans are prepared in several States and nationwide. Several alternatives for integration are proposed on the different planning levels. Finally, based on the recent French experience with creating SDAGE and SAGE, presented by the same authors in a recent paper, several recommendations are made for the water resources planning process in Brazil.

Key Words: water planning; water resources management; water resources management instruments.
\end{abstract}

